\title{
Unidad y dualidad de la coexistencia personal. El acceso a Dios desde el hombre, según Leonardo Polo
}

Unity and Duality of Personal Coexistence. Access to God from the Man, According to Leonardo Polo

JuAN A. GARCÍA GONZÁLEZ

Universidad de Málaga

juangarciagonzalez@gmail.com
RECIBIDO: ? DE ? DE 201? VERSIÓN DEFINITIVA: ? DE ? DE 201? DOI: $10.15581 / 013.19 .111-128$
Resumen: Se plantea en este trabajo el acceso antropológico a Dios tal y como pensamos que lo formula Polo: como la referencia de la dualidad propia del coexistir personal humano a la unidad de la existencia que es su identidad originaria. Para alcanzar esa referencia hay que dejar atrás otras dualidades y formas menores de unidad, o bien otras conjunciones del coexistente personal, que son tipos de coexistencia inferiores a la de la criatura personal con su creador.

Palabras clave: unidad, dualidad, coexistencia, réplica.
Abstract: Anthropological approach to God that arises in this work and we think it makes Polo: the reference of own duality coexisting human personnel to the unity of existence which is its original identity. To achieve that reference must leave behind other dualities and lesser forms of unit, or other coexistent conjunctions staff, which are rates below the coexistence of personal creature with its creator.

Keywords: Unity, Duality, Coexistence, Replica. 


\section{PLANTEAMIENTO}

$S$ egún Polo para considerar al hombre como vía hacia Dios, es preciso, desde el punto de vista de la filosofía, encontrar los trascendentales que le son propios (...): los trascendentales bumanos ${ }^{1}$ Y ello, en último término y como aquí vamos a ver, porque los trascendentales antropológicos ${ }^{2}$, los que corresponden al ser personal, son duales como éste. En su dualidad, esos trascendentales y ese ser remiten a Dios como la identidad originaria del existir; es decir, como a la réplica de que carecen, y que el hombre puede libremente buscar.

Sólo desde la dualidad de los trascendentales personales, por ser la última dualidad humana, tendremos el acceso adecuado a la originaria identidad divina. Otras dualidades en el hombre, nos ha advertido Polo, constituirían un defectuoso acceso a la identidad: otros modos de introducir prematuramente la identidad en antropología pueden ser sugestivos, pero no son legítimos; anticipar el tratamiento filosófico de Dios es desaconsejable ${ }^{3}$.

\section{El aCCESo a Dios DESDE la ANTROPOloGía Y DESDE LA METAFÍSICA}

Este acceso antropológico a Dios es, por otro lado, más fecundo que el acceso a Dios desde la criatura extramental ${ }^{4}$, porque los trascendentales humanos son superiores a los metafísicos. En último término, porque el ser personal es más digno que el natural; pues la persona, como señaló Tomás de Aquino, es el ser más digno de la realidad: persona significat id quod est perfectissimum in tota natura ${ }^{5}$; la persona, dice también Polo, es el axioma puro: axioma significa lo de más valor ${ }^{6}$.

Por esta misma razón, justamente, es por la que desde los trascendentales humanos se descubre la noción de réplica, en una primera y enteramente

1 "El descubrimiento de Dios desde el hombre", en Studia Poliana, 1 (1999), 11.

2 Sobre los trascendentales personales, cfr. J. F. SELLÉS, Antropología para inconformes, Rialp, Madrid, 2006, parte IV.

3 Antropología, I, 176.

4 Sobre la teología de Polo, cfr. J. F. SELLÉS, "La teología natural según Leonardo Polo", en Revista de bumanidades, 28 (2013), 45-69.

5 Summa theologiae I, 39, 3 c.

${ }^{6}$ Epistemología, edición de las obras completas (OC), 262. 
precisa aproximación a ella. Porque, en atención a la dignidad del ser personal, la meta, el fin, del entender ya no será tanto un trascendental metafísico -la verdad-como otro antropológico, el entender: de modo que, finalmente, el hombre se abre a su ser conocido por Dios. Y, análogamente, el término, el destino, del amar no será tanto el bien cuanto otro amar: pues el amar personal demanda correspondencia; en efecto, el sentido del dar está en el recíproco aceptar, en el ser aceptado: el amar se destina a la aceptación, dice Polo, y sin ella no nace.

De este modo surge la noción de réplica: aquella de que el hombre interiormente carece y libremente busca. La réplica que busca la persona humana es propia de la identidad originaria del ser divino, cuando es avistada desde los trascendentales personales: los propios de ese especial acto de ser que es el personal'; al que Polo llama, justamente en atención a su dualidad, co-ser, coexistencia. La réplica es, entonces, la identidad apuntada por la dualidad, y -con todo- superior al coexistir dual, que carece de ella: Dios es trascendens respecto de la coexistencia ${ }^{10}$.

De manera que nuestro conocimiento de la identidad mejora con la noción de réplica. Polo dice, en efecto, que la identidad de los trascendentales en el ser originario no puede entenderse suficientemente bien sin atender a los trascendentales personales: en el acto de ser originario los trascendentales son idénticos. Pero si no se alcanzan los trascendentales antropológicos, esta tesis no se puede sentar por completo ${ }^{11}$. O bien: si se omite la investigación acerca de la trascendentalidad de la intelección, del amar y de la libertad, el tema de la conversión de los trascendentales, así como el de su identidad real, no pueden enfocarse correctamente ${ }^{12}$.

Ya la tradición había señalado que el conocimiento de Dios desde el ser natural, mero vestigio del creador, era inferior al obtenido desde el ser personal, que es imago Dei. Paralelamente, afirma Polo, la distinción entre persistir y co-existir se corresponde con una distinción en el acceso a Dios. Si en metafísica Dios se advierte como identidad originaria, en antropología esa advertencia ba de ser conservada y recabada (...): Dios ba de ser originariamente persona. Pero si lo que ca-

\footnotetext{
${ }^{7}$ Antropología, I, 178.

8 "El descubrimiento de Dios desde el hombre", en Studia Poliana, 1 (1999), 24.

9 Sobre el ser personal, cfr. F. HAYA, El ser personal, Eunsa, Pamplona, 1997.

${ }^{10}$ Antropología, I, 178.

${ }^{11}$ Antropología, I, 205, nt. 7.

12 "El descubrimiento de Dios desde el hombre", en Studia Poliana, 1 (1999), 23.
} 
racteriza a la persona humana es la ausencia de réplica, en la persona originaria esa carencia no puede tener lugar ${ }^{13}$.

En virtud de su réplica originaria, hay que decir que, como Dios es persona, no será una única persona; pues -dice Polo- una persona única sería absurda ${ }^{14}$, algo sin sentido: la noción de persona única es completamente incoherente $^{15}$. Además, una persona única sería la tragedia pura (...); por eso, Dios no puede ser unipersonal (...): si fuera "monon”, la tragedia estaría en Dios mismo ${ }^{16}$.

La antropología trascendental Poliana, por tanto, acentúa la superioridad del acceso antropológico a Dios, como descubrimiento de su ser personal, al rechazar la unicidad de éste; rechazo sugerido desde la dualidad del ser personal creado, desde su carencia de réplica. Es decir, el planteamiento poliano añade al enfoque clásico de la persona como ser espiritual la incongruencia de la unicidad personal; $y$, por tanto, añade a la consideración del ser personal divino la noción de réplica: la réplica interna a la identidad originaria del ser; la identidad originaria de la existencia no carece de intimidad, ni es solitaria: pues tiene su réplica.

La noción de réplica del origen, dirá Polo, constituye un misterio inabarcable: no puede tratarse de otro origen, pues ello es incompatible con la identidad. Pero tampoco puede tratarse de una persona indistinta, porque ello conduce a entender la identidad en sentido corto -como mismidad-, lo que es incompatible con su carácter originario ${ }^{17}$.

De modo que, finalmente, la antropología trascendental permite vislumbrar la distinción personal en la identidad originaria (...), y es así el preámbulo de la fe en el misterio de la trinidad divina ${ }^{18}$.

${ }^{13}$ Antropología, I, 178.

${ }^{14}$ La justificación de la antropología trascendental está en que una persona sola es un absurdo: Economía, OC, 444.

15 "El descubrimiento de Dios desde el hombre", en Studia Poliana, 1 (1999), 20.

${ }_{17}$ Presente y futuro, 168.

17 Antropología, I, 178-179.

${ }_{18}$ Antropología, I, 179. Nos permitimos recoger una sugerencia: la discutida asociación aristotélica del primer motor con la "noesis noeseos" pide una reformulación. Porque no son dos seres distintos, ya que Dios es uno solo; pero tampoco son lo mismo, pues la mismidad del ser y el pensar es el límite mental, al que la identidad real anula. Sino que es la dualidad de personas interna a la identidad del ser originario: tal que, siendo ambas idénticas, la segunda es réplica de la primera. Porque la identidad originaria del ser no es sólo un primer principio; sino que, vista desde la coexistencia bumana, exige réplica personal. Por tanto, la unidad del ser divino no debe trasladarse a su ser personal: Dios es uno solo, pero no una sola persona. "Libertad trascendental y creación”, en Studia Poliana, 15 (2013), 135. 


\section{DESARROLLO}

\section{El PROBLEMA DE LA UNIDAD DE LA CRIATURA Y SU AGRAVAMIENTO} EN LA CRIATURA PERSONAL

Para desarrollar un poco este planteamiento de Polo, nos serviremos del problema que plantea a la unidad del ente creado la distinción real tomista entre la esencia y la existencia; pues, según dicha distinción, a la criatura no se le puede atribuir perfecta unidad, entera indivisión, ya que en ella se distinguen realmente dos -como se suelen denominar- coprincipios: la esencia y el acto de $\operatorname{ser}^{19}$.

Polo se enfrenta con este problema atribuyendo la unidad propiamente a Dios, que es la identidad originaria de la existencia. Y -efectivamente- ésa es, para la tradición, la que se denomina como esencia física de Dios: la unidad en simplicidad de todas las perfecciones del ser; no el sistema o constelación de todas las perfecciones en grado infinito, sino la simplicísima y absolutamente indivisible unidad de todas ellas ${ }^{20}$. En cambio, la unidad de la criatura es imperfecta, y propiamente deriva de su existencia: la unidad del ente creado, id quod babet esse, se toma del actus essendi.

Dice Polo, en efecto: el uno se toma primordialmente del "est" y no del "id quod" (...), luego la conversión del uno con el ser sería válida para el puro acto de ser, es decir, para el acto de ser divino (...); por su parte, la distinción real del acto de ser y la esencia impide la conversión con la unidad ${ }^{21}$. Si bien la misma conversión, en lugar de la estricta identidad, puede ser tomada ya como un modo imperfecto de unidad: la conversión -dice Polo- es un sentido de la unidad (perfecta o imperfecta $)^{22}$.

Pues bien: el problema de la unidad del ente creado se multiplica con la propuesta Poliana de ampliación trascendental de la metafísica con la antropología; es decir, con el añadido -en particular- del primero de los trascendentales humanos: el acto personal de coexistir como distinto del acto natural de ser. Porque, según esa ampliación, ya no tenemos sólo dos coprincipios, la esencia y el acto de ser de una criatura; sino que tenemos más: la esencia y el acto de ser del universo, y la esencia y el acto de co-ser de las personas. Como

${ }^{19}$ Cfr. Ma J. SOTO, "La criatura como distinción”, en Studia Poliana, 4 (2002), 141-165.

20 A. MILLÁN PUELLES, Fundamentos de filosofía, Rialp, Madrid, ${ }^{152012,} 564$.

${ }^{21}$ Antropología, I, 61.

${ }^{22}$ Antropología, I, 68, nt. 71. 
además, lo propio del coexistir personal es que se trata de un acto de ser segundo, que se añade a otro primero, con el que ha de reunirse o conjuntarse, se multiplica el problema de la unidad.

Con todo, si el coexistente se añade a la existencia, la inversa -en cambio- no se da; porque la primera criatura no coexiste: la coexistencia es propia de las personas. El co-existir -dice Polo- no se reduce al existir -con el que co-existe-: es una ampliación del existir. No se reduce a él; puesto que, por su parte, el ser del universo no co-existe con el ser bumano (...): la ampliación es propia del acto de ser que amplía ${ }^{23}$.

No sólo tenemos, entonces, el problema de la imperfecta unidad de la criatura, de cada criatura, por reunión de sus dos "coprincipios", esencia y ser; sino que tenemos ahora también una serie de problemas de unidad añadidos: que surge -ante todo- de la que llamamos conjunción del coexistente personal, y por serlo, con el existente natural, con los otros coexistentes y con el creador.

Precisamente hablamos de conjunción, no de colocación ni de composición $^{24}$, para nombrar la unión del coexistente personal, y justamente por ser coexistente, con otros seres. En vez de la unidad del ente creado, ahora tenemos otro problema de unidad distinto: la conjunción de una especial criatura, el coexistente personal, con el mero ente, la de los coexistentes entre sí y la del coexistente con su creador; conjunciones en algún caso subordinantes, mientras que en otros más bien coordinantes.

Como, además, el acto de coexistir corresponde a personas creadas, en las que también se distinguen esencia y acto de co-ser, tendremos que hablar entonces no sólo de coexistencia estrictamente dicha, sino también -y con algún mayor análisis y precisión- de coesencialidad. E incluso, como Polo llega a decir, de la esencialización de una existencia inferior por otro ser superior, según la cual lo que en el inferior era existencial en el superior es esencial; esencialización que, en el ser supremo, llegará a su cota máxima.

\section{LOS TIPOS DE COEXISTENCIA HUMANA}

En definitiva, cabe distinguir, sin acudir a una pura combinatoria entre los llamados coprincipios, estas distintas conjunciones:

${ }^{23}$ Antropología, I, 32-33.

${ }^{24}$ Sobre esos términos, cfr. Antropología, I, 242. 


\section{Una doble coesencialidad:}

La coesencialidad del hombre con el universo, por la dualidad entre el yo cognoscente y el yo actuante propia de la esencia humana ${ }^{25}$, puede dividirse en:

- una coesencialidad teórica, especialmente ubicada -pensamos- en la coordinación entre las causas físicas ${ }^{26} \mathrm{y}$ las operaciones racionales del hombre ${ }^{27}$;

- y otra coesencialidad práctica, de acuerdo con la cual -suele decir Polo- el hombre es el perfeccionador perfectible ${ }^{28}$ : ésta es la praxis técnica, la acción productiva del hombre. Por lo demás, el perfeccionamiento del universo se endereza al perfeccionamiento social de la esencia bumana ${ }^{29}$, al que ahora nos referiremos.

Esta doble coesencialidad es superior a la sola conmensuración de la operación mental con su objeto, de acuerdo con la cual decimos que el hombre está-en-el-mundo ${ }^{30}$ de un modo peculiar: objetivándolo; aunque, desde luego, sea imposible sin ella, sin la teoría humana ${ }^{31}$. Pero lo pensado, en tanto que intencional, más que de la esencia del hombre, forma parte de su naturaleza lógica: pues el término del objeto intencional no se incluye en la esencia bumana ${ }^{32}$.

\section{Dos tipos de coexistencia}

2. La coexistencia (y coesencialidad) entre las propias personas humanas.

Porque las personas creadas no coexisten entre sí en su intimidad existencial, sino sólo a través de su manifestación esencial; la sociedad es, en efecto, el estatuto de la manifestación humana en cuanto tal ${ }^{33}$ : el estatuto manifesta-

${ }^{25}$ Sobre esta dualidad, cfr. Antropología, II, 23.

${ }^{26}$ Sobre este tema, cfr. J. M. POSADA, La física de causas en Leonardo Polo, Eunsa, Pamplona, 1996.

27 Sobre esa coordinación, cfr. El universo físico, c. III: el logos predicamental.

28 Economía, OC, 149.

29 "La coexistencia del hombre", R. ALVIRA (Ed.), El bombre: inmanencia y trascendencia, Universidad de Navarra, Pamplona, 1991, 48.

${ }^{30}$ Cfr. Curso de teoría, II, lección 2a , 3, 52 ss. Cfr. sobre el tema J. J. SANGUINETTI, "El mundo como objeto de acción y teoría”, en Studia Poliana, 18 (2016), 27-50.

31 Sobre este punto, cfr. J. J. PADIAL, La antropología del tener según Leonardo Polo, Universidad de Navarra, Pamplona, 2000, c. II.

32 Antropología, II, 66.

${ }^{33}$ La sociedad es, en este sentido, el estatuto de lo manifiesto: lo humano está manifiesto en la sociedad: "La 'sollicitudo rei socialis': una encíclica sobre la situación actual de la humanidad". VV.AA., Estudios sobre la encíclica "Sollicitudo rei socialis", Unión Editorial, Madrid, 1990, 99. 
tivo del hombre, sin el cual no hay convivencia humana ${ }^{34}$. De manera que el hombre no sólo es un ser social por naturaleza, sino que es un ser esencialmente social $^{35}$.

$\mathrm{Y}$ al que por eso, precisamente, corresponde el perfeccionamiento en común de la humana naturaleza; pues, como los hombres disponen de una naturaleza común, les corresponde a todos ellos el perfeccionamiento de esa naturaleza: éste es el cometido de la praxis moral ${ }^{36}$.

Aunque la convivencia entre los seres humanos se establezca a través de su esencia, constituye sin embargo un tipo de coexistencia personal. Porque el ápice de la esencia del hombre, que Polo denomina querer-yo, depende del acto de ser personal, al que manifiesta; pues la sindéresis es un hábito que nace de la persona. Y -al tiempo- ese ápice es también intersubjetivo, interpersonal: querer-yo significa nos ${ }^{37}$.

3. Y la coexistencia entre el acto personal de ser y el acto de ser del universo, que compete al hábito de los primeros principios y constituye el saber propiamente metafísico.

El cual, para Polo, muestra la generosidad de la persona: que se olvida de sí y renuncia a actuar, a manifestarse, para advertir la mutua vigencia -entre sí, al margen del hombre- de los primeros principios.

4. La coexistencia personal estrictamente dicha: que es la coexistencia entre el acto de ser personal creado y el de su creador; propia del hombre que se orienta en busca de réplica y aceptación, aun sabiéndose carente de ellas.

El futuro encuentro de la réplica permitiría, por lo demás, sospechar una suerte de coesencialidad entre ambos que comportaría la saturación de las potencias superiores del hombre (la saturación de la inteligencia ba de reservarse a la vida post-mortem ${ }^{38}$, dice Polo), y la elevación de la esencia humana al plano del ser personal y por encima del hábito de los primeros principios: la esencia bumana está llamada -dice también- a alcanzar el nivel de los otros hábitos inna-

${ }^{34}$ Lecciones de ética, 129.

35 Cfr. sobre este punto F. MÚGICA, "El pensamiento social de Polo", Introducción a Sobre la existencia, 13-55.

${ }^{36}$ Cfr. J. F. SELLÉS, "The antropological foundation of ethics", en fournal of polian studies, 1 (2014), 47-77.

37 Antropología, II, 214.

38 Antropología, II, 79, nt. 106. 
tos. La superioridad post mortem del hábito de los primeros principios ${ }^{39}$ (e incluso su misma permanencia ${ }^{40}$ ) sería propia de lo que la vieja teología llamaba el limbo.

5. Y, finalmente, la esencialización de un ser: la esencialización del acto de ser del universo por parte de la persona humana. Ésta es una peculiar doctrina de Polo, envuelta en alguna ambigüedad.

a) En primer lugar, porque la esencialización humana del ser del universo no puede significar simetría entre ambos; esa simetría de la que Polo acusa al pensamiento moderno, y que impide la ampliación trascendental ${ }^{41}$.

La simetría se plasma, básicamente, en la noción de una subjetividad que se realiza espontáneamente: así como del ser surgen los entes, así del sujeto sus acciones y obras; sólo que libremente, esto es, de modo autónomo: la noción de sujeto reclama la de su autonomía.

Y la simetría se deshace en atención a la distinción real de esencia y existencia, en virtud de la cual-precisamente- se habla de esencialización de un acto de ser. Porque, aunque el hombre goza realmente de cierta autonomía en la vida práctica (la vida práctica -dice Polo- es en cierto modo autónoma ${ }^{42}$ ), la constitución del don esencial remite al ser personal ${ }^{43}$; y se distingue así de la pura autonomía: por el carácter destinal del don, que demanda la aceptación ajena, frente al carácter terminal de la acción para la realización del yo.

b) En segundo lugar, porque Polo concedió primero que la esencialización del ser del universo por parte del hombre correspondía al conocimiento, en particular al hábito de los primeros principios: ¿qué entiendo por esencialización del acto de ser extramental? -dice Polo- (...): entiendo su intelección ${ }^{44}$.

$\mathrm{Y}$, sin embargo, el hábito de los primeros principios es superior a la esencia humana. Con todo, hay que acudir a ese hábito y hablar de esencialización del ser, porque la existencia de toda criatura está exclusivamente referida al creador, y no a otra criatura: la actividad de las existencias creadas -dice, en efecto, Polo- sólo puede entenderse en referencia a Dios; y no, en cambio, en referencia a

39 Antropología, II, 299.

40 Antropología, II, 115, nt. 31.

${ }^{41}$ Cfr. La filosofía moderna como simetrización de la metafísica clásica. Antropología, I, 90 ss.

42 Antropología, II, 239.

${ }^{43}$ Cfr. U. FERRER, Acción: deber, donación; dos dimensiones éticas inseparables de la acción, Dikynson, Madrid, 2015, 206-207.

44 El universo físico, OC, 384. 
otra criatura $^{45}$. La metafísica no es, ni puede ser, una excepción a ello; sino que es un tipo de coexistencia de la persona humana con el acto de ser del universo: aquel que encuentra la verdad de éste.

Después, y finalmente, Polo se inclinó por afirmar que la esencialización del ser del universo acontece en la acción voluntaria del hombre ${ }^{46}$ : la cual se constituye como una corriente que se continúa hacia el futuro, así como la persistencia es la realidad de la secuencia -el seguir realmente- de antes a después. De acuerdo con esta nueva precisión, dice Polo, como el acto de ser del universo no es capaz de corresponder, quererlo significa esencializarlo ${ }^{47}$.

La armonización de ambas posiciones es posible en atención a la libertad personal: porque, dice Polo, sólo cabe esencializar la persistencia si la actividad libre no sufre menoscabo; los actos intelectuales esenciales no la esencializan porque son

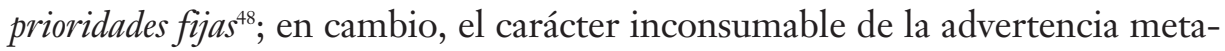
física, que es habitual, requiere también, por ceñida a la incesante persistencia, la aludida continuidad hacia el futuro.

A nosotros nos parece claro -además- que la causalidad trascendental como referencia de la persistencia a la identidad originaria del ser es "doblada" adecuadamente por la constitución del don característica de la esencia humana; ya que el dar y el aceptar ${ }^{49}$, que son trascendentales -existenciales-, han de completarse con el don, que -en el hombre- es sólo esencial y no existencial. La referencia del hombre al creador, en efecto, no es sólo existencial -en la búsqueda de réplica-, ni se reduce a su conocimiento incoativo mediante la demostración metafísica de la existencia de Dios; sino que también se manifiesta, y es -muy especialmente- esencial, operativa.

c) Con la noción de esencialización del ser tenemos, por otro lado, una segunda indicación sobre la noción de réplica: no sólo la identidad vislumbrada desde la dualidad de los trascendentales personales, sino tomada desde la dualidad creatural del ser y la esencia.

Desde este punto de vista, pueden pensarse también otras esencializaciones semejantes a la del ser del universo por la acción voluntaria del hombre. Son:

${ }^{45}$ Antropología, I, 242.

${ }^{46}$ Cfr. Antropología, II, 229.

${ }^{47}$ Antropología, II, 137, nt. 75.

48 Antropología, II, 236.

49 Sobre este punto, cfr. I. FALGUERAS, "Causar, producir, dar". Crisis y renovación de la metafísica, Universidad, Málaga, 1997, c. II. 
- la de la persona humana por parte de Jesucristo ${ }^{50}$, cuya esencia reúne e integra a todas las personas humanas: el alma de Cristo -dice Polo- sería la esencialización de la persona bumana ${ }^{51}$;

- y la esencialización divina -entera y completa- de su propio ser: la esencialización absoluta y sin resquicios del ser $^{52}$.

En este sentido, la noción de esencialización del ser permite un ascenso: del universo al hombre, del hombre a Jesucristo, y de éste a Dios; todas las cosas son vuestras, vosotros de Cristo y Cristo de Dios ${ }^{53}$.

De todas estas conjunciones propias del coexistente humano ha hablado expresamente Polo; y dan lugar, en último término, a los que Polo llama tipos de coexistencia del hombre ${ }^{54}$. Porque la coexistencia humana, su ser dual, está radicalmente referida al creador, a la réplica interior de que carece el hombre y a la que busca; pero se muestra y analiza además en otros diversos tipos derivados de ella.

Lo que acontece, ante todo, por ser el del hombre un acto de ser segundo, que se secundariza ${ }^{55} \mathrm{y}$ añade a otros; también por ser un acto de ser libre: con una libertad que no sólo se abre interiormente, sino que se extiende hacia fuera llegando hasta la acción práctica; y en definitiva, por ser el hombre una criatura: cuyo acto de ser se distingue finalmente de su esencia. Todo ello justifica los distintos tipos de coexistencia humana.

\section{LA RAÍZ DEL PROBLEMA DE LA UNIDAD DEL SER PERSONAL: \\ EL HOMBRE COMO SER DUAL}

Sobre todo, la coexistencia del ser humano nos lo muestra como un acto de ser dual ${ }^{56}$ : como co-ser. En la dualidad de su acto de co-ser encontramos la

\footnotetext{
${ }^{50}$ La persona de Jesucristo es divina, no humana; para que ello no comporte una disminución de su bumanidad sugiero la noción de esencialización del ser. Antropología, II, 299.

${ }^{51}$ Antropología, II, 229, nt. 293.

52 El hombre en la bistoria, 99.

531 Corintios 3,22-23.

${ }_{54}$ Cfr. Antropología, I, 206.

${ }_{55}^{5}$ La antropología estudia el ser segundo, es decir, el ser que se secundariza, el ser dual. Antropología, I, 213.

${ }^{56}$ Sobre el particular, cfr. S. PIÁ TARAZONA, El hombre como ser dual, Eunsa, Pamplona, 2001.
} 
raíz última de esa multiplicación señalada del problema de la unidad de la criatura personal.

Si toda criatura, por la composición real de esencia y existencia, tiene una unidad imperfecta, la criatura personal, por tener un acto de ser dual -por coexistir-, multiplica los sentidos de la unidad que le son propios, y agudiza así el problema de su unidad; hasta llegar a la que Polo denomina carencia de réplica interior y su ulterior búsqueda, que es la dualidad última del ser personal y sus trascendentales: la de la persona humana con su réplica ${ }^{57}$.

Esta dualidad de la coexistencia es propia del hombre, su acto de ser dual; pero en el hombre hay además otras muchas dualidades. Para llegar a la última, a la de los trascendentales antropológicos y la réplica de la persona, que es la que nos permite el acceso a Dios como identidad originaria del ser, hay que delimitar previamente cuáles son -en particular- las dualidades superiores del hombre ${ }^{58}$.

Ante todo hay que excluir la radicalidad de dos dualidades, por otro lado bien importantes en el hombre:

a) Primero está la dualidad, propia de toda criatura, que distingue la esencia y la existencia: en el hombre, el yo y la persona. Pero, dice Polo: la distinción real ser-esencia, por más que caracterice al hombre como criatura, no es la dualidad radical, porque en el hombre el ser es a su vez dual, si el acto de ser humano es acto como co-ser o co-existencia ${ }^{59}$.

b) Después está también, y como un requisito imprescindible, la dualidad de la persona humana con el acto de ser del universo; sin la cual el hombre no se abriría hacia fuera de sí mismo, y no sería corpóreo. Pues bien: la dualidad con el ser del universo, por remitir al ser personal y no exigir la mediación de la acción, es superior a la dualidad del ser con su esencia, y es así un tipo de coexistencia personal.

Excluida la ultimidad de estas dos dualidades, llegamos a la dualidad de los trascendentales personales con la réplica, la que permite el acceso a Dios; porque los trascendentales antropológicos inferiores muestran la carencia de réplica de la persona humana, y los superiores buscan esa réplica. $\mathrm{Al}$ alcanzar

${ }^{57}$ Cfr. U. FERRER, "Coexistencia y trascendencia”, en Studia Poliana, 14 (2012), 37-53.

${ }^{58}$ Cfr. al respecto J. F. SELLÉS, "Cuadro sobre las dualidades en las ciencias humanas según Polo", en Miscelanea Poliana, 49 (2015), 39-40.

59 Antropología, I, 177. 
la dualidad con la réplica el hombre encuentra la que hemos denominado como raíz del problema de la unidad personal: la dualidad de su co-ser; la carencia de réplica en su interior de la persona humana, que -con todo- permite su búsqueda.

Ésta es la dualidad última, inherente al propio acto de ser personal; y en virtud de la cual hablamos de co-ser o co-existencia. Conforme con ella, Polo señala que la coexistencia del hombre requiere un segundo con, co-existir-con ${ }^{60}$ : el hombre coexiste en su interior con su creador; una persona sola es absurda ${ }^{61}$.

\section{LA DUALIDAD LIBRE DE LOS TRASCENDENTALES PERSONALES}

La dualidad del coexistir personal con la réplica, de la que carece y a la que busca, incluye a su vez otra dualidad derivada, pero propia también de los trascendentales humanos -y que precisará el modo de su conversión: según el criterio de la dualidad ${ }^{62}$-; porque no es lo mismo carecer de réplica que orientarse en su busca. Distinguir esta nueva dualidad (no sólo la dualidad de la persona humana y la réplica; sino la dualidad entre carecer de réplica y buscarla en quien la tiene) nos permitirá ordenar o jerarquizar los trascendentales personales. Por lo demás, esta segunda dualidad deriva estrictamente de la libertad trascendental de la persona, es decir, de la posesión de futuro propia del ser personal: porque no es lo mismo alcanzarse desde el presente, como un ser al que conviene el carácter de además y que carece de réplica, que buscarse en el futuro, orientándose en busca de la réplica.

a) El primer e inferior miembro de esta dualidad derivada constituye la que Polo llama apertura interior de la persona: pues el acto personal de ser está abierto por dentro. La coexistencia personal se alcanza; y se describe, inicialmente, como intimidad, como co-ser; cuya inmediata actividad es la libertad. En su intimidad, el hombre descubre la carencia de réplica, o que él es una persona sola: que no es dos personas, y también que no es única o aislada ${ }^{63}$.

Desde la metodología de Polo, la apertura interior del hombre se aclara considerando el doble valor, metódico y temático, del carácter de además de

${ }^{60}$ Antropología, I, 165.

${ }^{61}$ La noción de persona excluye de raíz el monismo: J. F. SELLÉS, "La realidad que subyace, según Leonardo Polo, bajo el concepto de persona", en Estudios filosóficos polianos, 1 (2014), 6.

${ }_{62}$ Antropología, I, 204, nt. 4.

63 Antropología, I, 204. 
la persona ${ }^{64}$; en particular, el ajuste entre el hábito de sabiduría, que es el método, y los trascendentales personales, que son su tema. El hombre, además de todo lo que ve y encuentra fuera de sí al inteligir ${ }^{65}$, sabe en su interior de sí mismo, de su propia existencia libre; es el valor metódico del carácter de además: el hábito de sabiduría. Aunque los trascendentales antropológicos son su temática, sólo esos dos inferiores -la coexistencia y la libertad- se ajustan con él.

Que el saber humano se ajuste propiamente con los trascendentales antropológicos inferiores acontece, en el fondo, porque la sabiduría humana está separada de su temática, justamente en virtud de la libertad trascendental: $e l$ bábito de sabiduría -dice Polo-, considerado estrictamente, está separado de los trascendentales personales, que son su temática propia. Esta consideración es posible en cuanto que uno de los trascendentales alcanzados es la libertad ${ }^{66}$.

Lo que ocurre porque, cuando se trata de la libertad trascendental, no es menester admitir la solidaridad entre el método y el tema $a^{67}$. Por eso, la libertad personal -como tema- no remite a otro tema, sino que se reduce a ratificar su alcance metódico. El valor metódico de la libertad trascendental es la libertad nativa del hombre; la cual es metódica ${ }^{68}$ porque es la posesión de futuro, que abre caminos. $\mathrm{Y}$ el sentido temático de la libertad trascendental es la libertad de destinación; pero esta libertad no remite a otro tema, salvo por conversión con el entender y amar personales, sino que se ajusta con el futuro poseído: es la proyección o comunicación del futuro ${ }^{69}$ a los trascendentales superiores.

b) Por mor de la libertad, la apertura interior de la persona humana se distingue de su apertura hacia dentro, que es el segundo y superior miembro de la dualidad, que decimos derivada, propia de los trascendentales humanos.

Sin esta dualidad, que distingue en el hombre las aperturas interior y hacia dentro, no podría el ser humano -criatura referida al creador- completar libremente el acceso antropológico a Dios. Desde la carencia de réplica, el

64 Cfr. Antropología, I, 194 ss.

65 Sobre este punto, cfr. J. M. POSADA, "La intencionalidad del inteligir como iluminación”, en Miscelanea Poliana, 12 (2007), 9-33.

66 Antropología, I, 237.

67 Antropología, I, 237.

${ }^{68}$ La libertad nativa es el sentido metódico de la libertad: Antropología, I, 236. Por su parte, la libertad esencial es método de cabo a rabo: Antropología, II, 25.

69 Polo señala que así se evita la confusión de Dios con el futuro que achaca a Rahner; cfr. Antropología, I, 231, nt. 51. 
hombre -hacia dentro- se trueca libremente en su busca; ello apela a los trascendentales antropológicos superiores: el entender y el amar.

Desde ellos Polo nos ofrece una tercera y muy expresiva indicación de la noción de réplica: su descripción como otro semejante, noción que reúne las intencionalidades de voluntad e inteligencia ${ }^{70}$.

En el acceso antropológico a Dios, los trascendentales humanos superiores tienen sólo un sentido temático, ya que se absuelven, se desligan, van más allá de su valor metódico, del valor metódico del carácter de además que es el hábito de sabiduría, para orientarse en busca de la réplica. Entonces, el hombre depone su propia sabiduría; y por esta razón el abandono del límite no da más de $s i^{11}$; y cede el paso a la búsqueda de réplica, que no es una dimensión del método propuesto ${ }^{72}$ por Polo para la filosofía.

\section{LA CONVERSIÓN DE LOS TRASCENDENTALES ANTROPOLÓGICOS}

Por la dualidad humana entre la apertura interior y la apertura hacia dentro, o entre los trascendentales antropológicos inferiores y superiores ${ }^{73}$, la conversión de los trascendentales personales no es una mera equivalencia.

Sino que comporta una profundización en la intimidad humana, desde el interior hacia dentro, que requiere la comunicación de la libertad a los trascendentales superiores: la proyección hacia el futuro, en búsqueda, del intelecto y amar personales.

Comunicación según la cual se produce el trueque del valor metódico del carácter de además de la persona por su valor temático. La persona humana no sólo es el tema que alcanza la propia sabiduría, sino que -depuesta ésta- es además tema de la sabiduría divina; el carácter de además de la persona humana tiene así también sentido temático. Por eso el hombre, que se sabe carente de réplica, se orienta en busca de ella: se abre al conoceré como soy conocido $0^{74}$ y también a dar, en busca de la futura aceptación de su don.

Cfr. Persona y libertad, 253.

${ }^{71}$ Antropología, I, 11.

72 Antropología, I, 212.

${ }^{73}$ Nos cabe sugerir que los trascendentales personales inferiores y superiores (como también respectivamente los primeros principios de no-contradicción y de causalidad trascendental) se distinguen en función de la esencia, porque los últimos cuentan de algún modo con ella, no sólo se distinguen de ella.

${ }^{74}$ Antropología, I, 226, nt. 41, citando: 1 Corintios 13,12. 
El carácter de además de la persona humana, por tanto, no sólo tiene un sentido metódico, con el que se alcanza la propia coexistencia carente de réplica; sino además otro temático, que permite buscar la réplica de que ella interiormente carece. El carácter de además del ser personal, en definitiva, no sólo es el método para alcanzarse como coexistente, como alguien que existe además de ejercer las operaciones mentales con sus respectivos objetos; sino que también es el tema que se busca después, además y por encima de su propio alcance metódico.

El doble valor -metódico y temático-, enteramente solidario, del carácter de además de la persona humana ${ }^{75}$ da razón de ese mencionado trueque. El cual es una continuación del coexistir personal, mediante la cual el hombre se orienta hacia la réplica: en su busca. La persona humana no es, como la divina, relación subsistente; pero sí subsistencia que, carente de réplica, se torna relación a ella: buscándola; subsistencia, pues, que se continúa en relación: no una relación subsistente, sino el no detenerse ni precipitar de la subsistencia bumana basta la relación subsistente ${ }^{76}$; porque toda criatura, también la libre, dice relación al creador.

Según la conversión de los trascendentales humanos, de los inferiores a los superiores, tenemos ya la orientación de la persona humana hacia su creador. La cual, aunque afecte en general a todos los trascendentales antropológicos, sólo es temática en los superiores; que por eso constituyen la apertura hacia dentro de la persona humana: al mudar la carencia de réplica, en su busca con el entender y el amar. La orientación (según la búsqueda de réplica)-dice Polo- es propia de los trascendentales antropológicos, los cuales se convierten de acuerdo con ella, pues todos apuntan a la trascendencia. Sin embargo, en la co-existencia y en la libertad personal ese apuntar es temático sólo por conversión con los trascendentales que buscan ${ }^{77}$.

Al buscar la réplica, el entender busca su ser entendido, y el dar busca su ser aceptado; ambos remiten al creador. Como el conocimiento y la predilección divinos $^{78}$ explican la creación del hombre, en el encuentro de la réplica -si

${ }^{75}$ Éste es el significado estricto del carácter de además: el carácter sobrante tanto de su valor metódico como de su valor temático: Antropología, I, 194.

76 ...hasta la asimilación al Hijo de Dios: "La persona humana como relación en el orden del origen", en Studia Poliana, 14 (2012), 28.

77 Antropología, I, 213, nt. 17.

${ }^{78}$ Soy exclusivamente porque Dios ha querido que sea: y dicho querer es un acto de predilección divina. No hay otra explicación: Introducción, 211. 
aconteciere- el hombre alcanzará el conocimiento de su propio ser creado. Que es la plenitud, si no atendemos a las ulteriores revelación y elevación gratuitas, de la libertad personal que le ha sido otorgada al hombre por el creador; y que en esta vida es sólo pretemática: la libertad plena de la primera creación es la iluminación temática del don cuyo hontanar es Dios (...): la persona ilumina su propia creación, que hasta entonces es la fase atemática de la libertad ${ }^{9}$.

\section{CONCLUSIÓN}

\section{El COEXISTENTE HUMANO Y SU RÉPLICA}

Concluyamos.

Nuestra opinión es que -en algún sentido, es decir, al margen ya de cualquier simetría- el hombre es la réplica del universo ${ }^{80}$, puesto que esencializa su ser: con su acción práctica produce una segunda naturaleza. Pero si -al menos hasta cierto punto- el hombre es la réplica del universo, la inversa no ocurre: el hombre no encuentra otro semejante a él en su coexistencia y coesencialidad con el universo.

En cambio, el ser humano sí encuentra cierta réplica -otro como él- en su coexistencia (y coesencialidad) con las demás personas humanas. La coexistencia bumana -dice Polo- carece de réplica, pero su esencia no; mejor dicho, existen una pluralidad de personas humanas que se encuentran a través de sus respectivas esencias $^{81}$; pues todos los seres humanos somos coexistentes que nos manifestamos en sociedad; el amigo, como dijo Aristóteles, es otro yo ${ }^{82}$. Pero el hombre no encuentra su réplica estricta -entera y definitiva- en las personas creadas, que son más bien dúplicas que réplicas por ser externas a la persona.

Pero en su interior, el hombre no encuentra réplica. Como lo suele decir Polo, el yo pensado no piensa ${ }^{83}$; el saber sobre sí propio de la persona humana es un hábito, una posesión o cualidad nativa del intelecto personal, pero no es persona. El hombre, siendo radicalmente coexistente, está interiormente solo.

\footnotetext{
${ }^{79}$ Antropología, II, 238.

${ }^{80}$ Con todo, Polo vacila en esta opinión; y ha discutido mucho con el pensamiento moderno si el hombre podía ser tomado como réplica del universo o quizá no. Véase "La coexistencia del hombre", en R. ALVIRA (Ed.), El hombre: inmanencia y trascendencia, Universidad de Navarra, Pamplona, 1991.

81 Antropología, II, 12.

${ }^{82}$ Cfr. al respecto "La amistad en Aristóteles", en Anuario filosófico, 32-2 (1999), 477-485.

${ }^{83}$ Nietzsche, 215.
} 
Si a ello se añade que el acto de ser persona es subsistente, y en paralelo el alma espiritual inmortal, la soledad perpetua de la persona resulta desesperante y trágica. El coexistente personal estaría abocado a encontrarse sólo con lo inferior a él, con lo externo, o con lo impersonal. Por eso, dice Polo, la ausencia definitiva de réplica dejaría al hombre inédito, como un penoso misterio sin resolver: si no encuentra la réplica, la persona es para ella misma un misterio ${ }^{84}$.

Mas la carencia de réplica del ser humano no tiene por qué ser definitiva, y por eso el hombre puede libremente buscar la réplica. Y, dado el caso, encontrarla en el verbo divino: la réplica originaria del ser, en toda su omnitud. Porque sólo ella desvelará al hombre su verdad última, pues finalmente lo juzgará y -en su caso- podrá aceptarlo: la consumación de la aceptación divina es el juicio (...); renunciar a ser juzgado equivale a quedar sumido en la perplejidad ${ }^{85}$.

Luego el hombre, como coexistente, como ser al que corresponde el carácter de además, pero que carece de réplica, es -en definitiva- el adverbio que se añade al verbo divino: la asimilación adverbial al hijo ${ }^{86}$ de Dios. Es lo que dice Polo, como una glosa al maestro Eckhart: quien lo indicó al decir que el bijo de Dios es el verbo, y el hombre el adverbio ${ }^{87}$.

\footnotetext{
Economía, OC, 444.

Antropología, I, 221.

Antropología, I, 214.

${ }^{87}$ Antropología, I, 118.
} 